\title{
First trimester spontaneous rupture of an unscarred uterus in a multiparous woman: a case report
}

\author{
Ahmed M. Abbas, ${ }^{1}$ Amera M. Sheha, ${ }^{2}$ Mohamed Abdallah, ${ }^{1}$ Sara Abdullah, ${ }^{2}$ Mohamed \\ Bahaa $^{2}$
}

Keywords: Uterine rupture, maternal morbidity, first trimester

\begin{abstract}
The rupture of an unscarred uterine is a rare lifethreatening event that usually occurs late in pregnancy or during labor. Spontaneous uterine rupture, as in our case, is extremely uncommon and rarely diagnosed before laparotomy. Herein, we present a case of spontaneous uterine rupture in a 32 year old multiparous woman with no previous uterine surgery. The patient presented with acute abdomen at 11 weeks of gestation. Preoperative diagnosis based on clinical and ultra-sonographic findings was ruptured ectopic pregnancy. However, emergency laparotomy showed uterine rupture with extrusion of a dead fetus within intact amniotic sac in the abdomen. The defect was repaired in layers and the patient was discharged in a good condition after five days of hospital stay. Multiparity is a risk factor for spontaneous uterine rupture even in the first trimester. It should be kept in mind in any pregnant multiparous woman presenting with acute abdomen and shock. The absence of vaginal spotting and lack of history of uterine surgery give a false sense of security.
\end{abstract}

${ }^{1}$ Department of Obstetrics and Gynecology, Faculty of Medicine; Assiut University, Assiut, Egypt

${ }^{2}$ Faculty of Medicine; Assiut University, Assiut, Egypt

\section{Introduction}

The rupture of a gravid uterus is one of the life-threatening obstetrical emergencies, associated with poor fetal and maternal outcome..$^{1,2}$ It is fairly common in the third trimester of pregnancy ranging between 1/8000 to $1 / 15000$ pregnancies. ${ }^{3}$ There are no previous reports about the true incidence of first-trimester uterine rupture uterus with most reports being case reports or small case series.

There are many conditions associated with an increased risk of uterine rupture in the first trimester of pregnancy. Some of these risk factors include: uterine

Please cite this paper as: Abbas AM, Sheha AM, Abdallah M, Abdullah S, Bahaa M. First trimester spontaneous rupture of an unscarred uterus in a multiparous woman: a case report. Proc Obstet Gynecol. 2017;7(1): Article 7 [ 6 p.]. Available from: http://ir.uiowa.edu/pog/ Free full text article.

Corresponding author: Ahmed M. Abbas, MD, Department of Obstetrics and Gynecology, Faculty of Medicine; Assiut University, Assiut, Egypt; Woman's Health Hospital, 71511, Assiut, Egypt, Cellular: +20 10033851833; Tel: +2088 2414616; email: bmr90@hotmail.com

Financial Disclosure: The authors report no conflict of interest.

Copyright: (c) 2017 Abbas et al. This is an open-access article distributed under the terms of the Creative Commons Attribution License, which permits unrestricted use, distribution, and reproduction in any medium, provided the original author and source are credited. 
anomalies, $^{4,5}$ use of misoprostol, ${ }^{6}$ placenta percreta, multiparity with short inter-delivery interval, previous cesarean section (CS) or other uterine surgeries and uterine curettage. However, previous CS is the most important factor, ${ }^{1}$ especially in the second and third trimesters. ${ }^{1,7}$

The spontaneous rupture of an unscarred gravid uterus is extremely rare especially in the first trimester with no definite history of any associated risk factor. There are no pathognomonic features of uterine rupture in early pregnancy and it should be differentiated from other causes of acute abdominal emergencies. Here, we report a case of this catastrophic complication in a multiparous woman in the $11^{\text {th }}$ week of gestation with no other risk factor that could have resulted in uterine rupture.

\section{Case history}

In August 2016, a 32-year-old, gravida 6 , para $5+0$, presented to the emergency unit of Assiut Women's Health Hospital, Egypt at 11 weeks of gestation (based on her last menstrual period) with acute onset of severe lower abdominal pain. She had no history of previous CS, any other uterine surgery, or IUD insertion. Previously the patient had two antenatal visits with ultrasound confirmation of an intrauterine pregnancy.

On general examination, the patient was pale, her pulse 130 beats/min, blood pressure $90 / 60 \mathrm{mmHg}$, and temperature $37^{\circ} \mathrm{C}$. An abdominal examination revealed generalized tenderness and rebounding all over her abdomen. Pelvic examination showed a closed cervix and very tender enlarged uterus. Neither adnexa was palpable. There was no vaginal discharge or bleeding.

Transabdominal ultrasound scan revealed a bulky empty uterus with marked free intraperitoneal fluid collection, a single fetus in an intact gestational sac with absent cardiac activity measured 10.4 weeks by crownrump length. Hematological examination showed a hemoglobin level (HB) of 7.2 g/dl.

The patient was counseled concerning the possibility of a ruptured ectopic pregnancy, and informed consent for abdominal exploration was obtained. Exploratory laparotomy though a Pfannenstiel's incision was performed under general anesthesia. Surprisingly, on opening the peritoneal cavity, free blood collection was noted with a defect in the fundus about $2 \times 2 \mathrm{~cm}$ and the gestational sac with the dead fetus outside the uterus (Figure 1).

The fetus was removed from the abdomen and the defect was repaired in two layers by non-absorbable sutures (Figure 2). The abdomen was closed in layers after normal saline lavage. The patient received $2 \mathrm{~L}$ of whole crossmatched blood during the operation. The estimated intraoperative blood loss was $1500 \mathrm{cc}$. The patient had a smooth recovery from anesthesia and then she was transferred to the postoperative care room. She passed flatus 12 hours after surgery and defecated the next morning. Postoperative HB level was $10.0 \mathrm{gm} / \mathrm{dl}$. The postoperative course was uneventful and the patient was discharged on the 5 th day. 


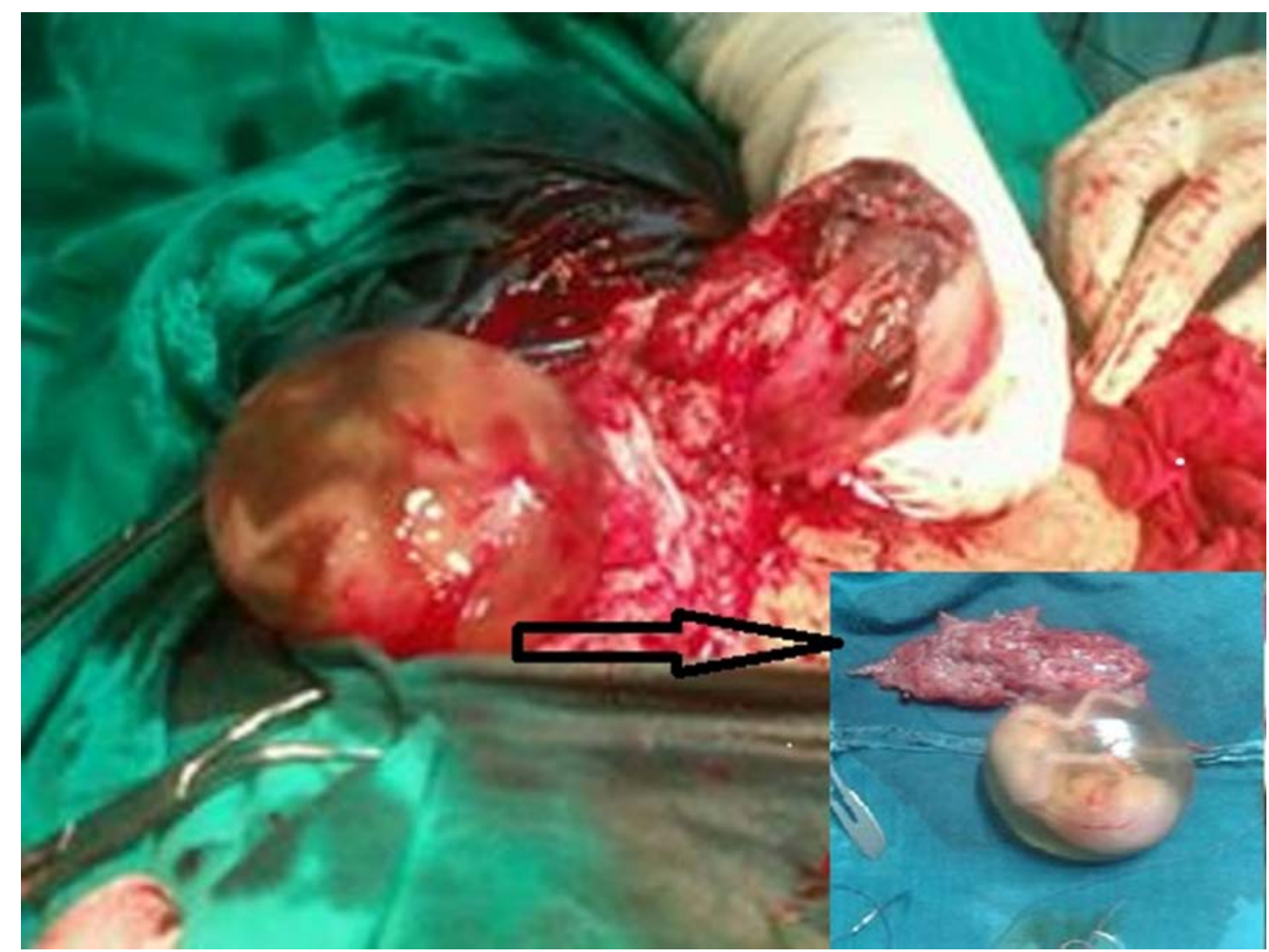

Figure 1: Rupture uterus; the uterus shows a fundal defect with intact gestational sac outside it contains an 11 weeks fetus

\section{Discussion}

Spontaneous uterine rupture is a rare dangerous obstetric complication that is associated with maternal mortality and morbidity rates between $20.8 \%$ and $64.6 \% .^{8}$ The most important factor implicated in uterine rupture is previous uterine scarring. ${ }^{9}$ Rupture of an unscarred uterus is associated with various factors such as high parity, ${ }^{10}$ abnormal placentation, uterine anomalies, malpresentation, obstetric maneuvers and injudicious use of oxytocics $^{11}$ or it may be of unknown cause. ${ }^{12}$ Most of these causes occur in the third trimester of pregnancy or during labor.
Spontaneous uterine rupture in the first trimester is a rarity especially in the absence of associated risk factors. The incidence of uterine rupture in unscarred uterus is 0.7 per 100,000 deliveries and 5.1 per 100,000 deliveries in scarred uterus $^{13}$. In our case past obstetric history was not significant and there were no known risk factors for uterine rupture except for being multiparous with previous five vaginal deliveries.

Although abdominal pain, vaginal spotting and vomiting are the classic findings in cases of uterine rupture, it is difficult to diagnose early uterine rupture depending on these non-specific findings as which also occur in other 
conditions such as molar pregnancy with invasion and ectopic pregnancy. ${ }^{9}$ Furthermore, symptoms and signs of intra-abdominal bleeding with uterine rupture, especially in unscarred uterus, are subtle. ${ }^{14}$

The lower uterine segment, which is the weakest part, is a common site of unscarred third trimester uterine rupture, ${ }^{15}$ while fundal rupture occasionally occurs with first trimester rupture $^{16}$ and is associated with late diagnosis due to free blood collection in the intra-peritoneal space. ${ }^{15}$

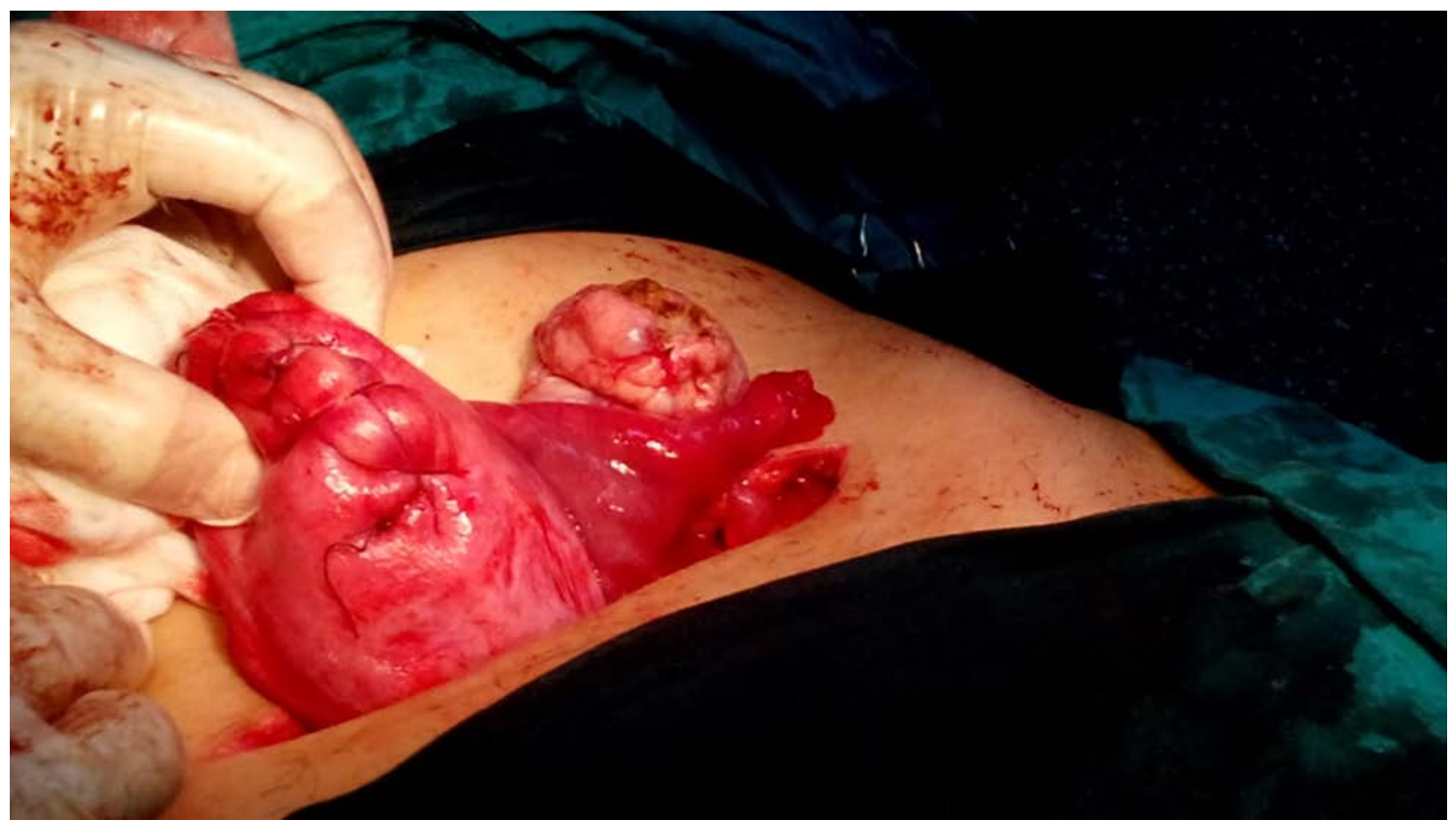

Figure 2: Repair of the fundal rupture in two-layers.

In our case, an important point to note is the occurrence of uterine rupture in the first trimester in a woman with no history of uterine surgery or any other risk factor except for multiparity. Uterine rupture in multiparous women may be due to repeated stretching and thus weakening of the myometrium which makes it more prone to rupture. By searching in the literature we found few reported cases of spontaneous uterine rupture in early pregnancy with no previous risk factor. ${ }^{9,16-19}$ In our case rupture occurred in $11^{\text {th }}$ week of gestation in a multiparous woman with an unscarred uterus.

Early uterine rupture and ectopic pregnancy are confusing for the obstetricians $^{18}$ and usually not differentiated till laparotomy. Ultrasound may help in diagnosis but any other preoperative evaluation wastes precious surgical time. Early surgical intervention 
is required to prevent the catastrophic events of uterine rupture. Surgical options include suturing of the defect with or without tubal ligation, subtotal and total hysterectomy. Extent of the lesion, desire to preserve future fertility, condition of the patient and surgeon's experience are determining factors for the nature of surgery. In the case of uterine repair without tubal ligation, the patient should be counseled about the risk of rupture in subsequent pregnancies which is estimated between $4 \%$ \& $19 \%$. $^{20}$

This case highlights multiparity as a risk factor for spontaneous first trimester uterine rupture. It is associated with poor fetal and maternal outcome due to difficult prediction by obstetricians in the absence of risk factors and due to rapid bleeding. Obstetricians must keep it in mind when a pregnant woman presents with acute abdomen in early pregnancy even with the absence of any risk factors.

\section{Conclusions}

High parity is a major risk factor for unscarred uterine rupture. Clinical signs and symptoms are non-specific in early pregnancy. Immediate laparotomy is the key for successful treatment.

\section{References}

1. Turner MJ. Uterine rupture. Best Pract Res Clin Obstet Gynaecol. 2002 Feb;16(1):69-79. https://doi.org/10.1053/beog.2001.0256 PubMed PMID: 11866498.
2. Kieser KE, Baskett TF. A 10-year population-based study of uterine rupture. Obstet Gynecol. 2002 Oct;100(4):749-53. https://doi.org/10.1097/00006250200210000-00022 PubMed PMID: 12383544.

3. Sun $H D$, Su $W H$, Chang $W H$, Wen $L$, Huang BS, Wang $\mathrm{PH}$. Rupture of a pregnant unscarred uterus in an early secondary trimester: a case report and brief review. J Obstet Gynaecol Res. 2012 Feb;38(2):442-5. https://doi.org/10.1111/i.14470756.2011.01723.x PubMed PMID: 22229814.

4. Tsafrir A, Rojansky N, Sela HY, Gomori JM, Nadjari M. Rudimentary horn pregnancy: first-trimester prerupture sonographic diagnosis and confirmation by magnetic resonance imaging. J Ultrasound Med. 2005 Feb;24(2):21923.

https://doi.org/10.7863/jum.2005.24.2.21 g PubMed PMID: 15661954.

5. Abbas AM, Ali SS, Sheha AM, Talaat E, Gamal E. A near miss case of ruptured non-communicating rudimentary horn pregnancy in primigravida. Middle East Fertility Society J. 2016; http://dx.doi.org/10.1016/..mefs.2016.08. $\underline{002}$ (In press).

6. Abbas AM, Sheha AM, Hussein RS, Talaat E, Ali MN. First-trimester rupture of a scarred uterus after use of sublingual misoprostol: a case report. Proc Obstet Gynecol. 2016;6(2): Article 5 [ 6 p.]. Available from: http://ir.uiowa.edu/pog/

7. Kong KY, Jang SK, Lee JY, Chung JK, Kim YJ. A clinical evaluation on the rupture of the gravid uterus. Korean $\mathrm{J}$ Obstet Gynecol. 1993 Jul;36(7):14861490. Korean 
8. Schrinsky DC, Benson RC. Rupture of the pregnant uterus: a review. Obstet Gynecol Surv. 1978 Apr;33(4):217-32. https://doi.org/10.1097/00006254197804000-00001 PubMed PMID: 347349.

9. Ijaz S, Mahendru A, Sanderson D. Spontaneous uterine rupture during the $1^{\text {st }}$ trimester: a rare but life-threatening emergency. J Obstet Gynaecol. 2011 Nov;31(8):772.

https://doi.org/10.3109/01443615.2011. 606932 PubMed PMID: 22085077.

10. Miller DA, Goodwin TM, Gherman RB, Paul RH. Intrapartum rupture of the unscarred uterus. Obstet Gynecol. 1997 May;89(5 Pt $\quad$ 1):671-3. https://doi.org/10.1016/S00297844(97)00073-2 PubMed PMID: 9166298.

11. Uzun I, Yildirim A, Kalelioglu I, Has R. Spontaneous rupture of unscarred uterus at 27 weeks of gestation. Arch Gynecol Obstet. 2010 Jun;281(6):9991001. https://doi.org/10.1007/s00404009-1321-8 PubMed PMID: 20033422.

12. Chigbu B, Onwere S, Kamanu C, Aluka C, Adibe E, Onichakwe C. Rupture of the uterus in a primigravida: a case report. Niger J Clin Pract. 2010 Jun;13(2):233-4. PubMed PMID: 20499765.

13. Abdulwahab DF, Ismail $H$, Nusee $Z$. Second-trimester uterine rupture: lessons learnt. Malays J Med Sci. 2014 Jul;21(4):61-5. PubMed PMID: 25977625; PubMed Central PMCID: PMC4418117.

14. Walsh CA, Baxi LV. Rupture of the primigravid uterus: a review of the literature. Obstet Gynecol Surv. 2007 May;62(5):327-34; quiz 353-4. https://doi.org/10.1097/01.ogx.00002616 43.11301.56 PubMed PMID: 17425811.
15. Misra M, Roychowdhury R, Sarkar NC, Koley MM. The spontaneous prelabour rupture of an unscarred uterus at 34 weeks of pregnancy. J Clin Diagn Res. 2013 Mar;7(3):548-9. https://doi.org/10.7860/JCDR/2013/4496 .2820 PubMed PMID: 23634419; PubMed Central PMCID: PMC3616579.

16. Park YJ, Ryu KY, Lee JI, Park MI. Spontaneous uterine rupture in the first trimester: a case report. J Korean Med Sci. $2005 \quad$ Dec;20(6):1079-81. https://doi.org/10.3346/jkms.2005.20.6.1 079 PubMed PMID: 16361828; PubMed Central PMCID: PMC2779315.

17. Biljan MM, Cushing $\mathrm{K}$, McDicken IW, Garden AS. Spontaneous uterine rupture in the first trimester of pregnancy. J Obstet Gynaecol. 1996;16(3): $\quad$ 174-5. http://dx.doi.org/10.3109/014436196090 $\underline{04098}$

18. Singh A, Jain S. Spontaneous rupture of unscarred uterus in early pregnancy-a rare entity. Acta Obstet Gynecol Scand. 2000 May;79(5):431-2. https://doi.org/10.1080/.16000412.2000.079005431.x PubMed PMID: 10830773.

19. Dibbs KI, Ball RH, Huettner PC. Spontaneous uterine rupture and hemoperitoneum in the first trimester. Am J Perinatol. 1995 Nov;12(6):439-41. https://doi.org/10.1055/s-2007-994516 PubMed PMID: 8579658.

20. Ahmadi S, Nouira $M$, Bibi $M$, Boughuizane S, Saidi H, Chaib A, Khairi $\mathrm{H}$. [Uterine rupture of the unscarred uterus. About 28 cases]. Gynecol Obstet Fertil. $2003 \quad$ Sep;31(9):713-7. http://dx.doi.org/10.1016/S12979589(03)00212-1 PubMed PMID: 14499715. French. 